\title{
SPECTRUM OF BACTERIA ISOLATED FROM BRONCHOALVEOLAR LAVAGE IN A TERTIARY CARE CENTRE
}

Sowmya K. N ${ }^{1}$, Sevitha Bhat ${ }^{2}$, K. Vishwas Saralaya ${ }^{3}$

\section{HOW TO CITE THIS ARTICLE:}

Sowmya K. N, Sevitha Bhat, K. Vishwas Saralaya. "Spectrum of Bacteria Isolated from Bronchoalveolar Lavage in a Tertiary Care Centre". Journal of Evolution of Medical and Dental Sciences 2014; Vol. 3, Issue 28, July 14;

Page: 7950-7954, DOI: 10.14260/jemds/2014/2995

ABSTRACT: BACKGROUND/OBJECTIVES: Pneumonia is an inflammatory condition of the lung caused by bacteria, viruses, fungi and parasites. The common bacterial pathogens include Pseudomonas spp., Klebsiella pneumoniae, S. aureus, Acinetobacter spp., Streptococcus pneumoniae. Antibiotic resistance is common among these bacterial isolates. This study was taken up to identify the spectrum of bacteria isolated from bronchoalveolar (BAL) samples of patients suffering from lower respiratory tract infections and to determine their antibiogram. MATERIALS and METHODS: The retrospective study was carried out in a tertiary care centre over a period of one year (March 2013-February 2014).Patients above 18 years with clinical suspicion of pneumonia were included in this study. The samples with growth $>10^{4} \mathrm{CFU} / \mathrm{ml}$ of bacteria were identified and their susceptibility pattern to various antibiotics was performed. RESULTS: Out of 307 BAL samples, 110 were culture positive. The common bacterial pathogens isolated were Pseudomonas spp. (21.8\%), Acinetobacter spp. (15.5\%), Klebsiella spp.(14.5\%), Enterococcus spp.(10.9\%) and S.aureus (12.7\%). Carbapenem resistance was seen in 31.6\% of Acinetobacter spp, 22\% Klebsiella spp. and 14\% in Pseudomonas spp. Methicillin resistance was detected in $21.4 \%$ of S.aureus isolates. All strains of S.aureus were sensitive to vancomycin and teicoplanin. All isolates of Enterococci were sensitive to vancomycin, teicoplanin and high level aminoglycosides. CONCLUSION: Pseudomonas and Acinetobacter spp. were the most common bacterial pathogens isolated from BAL. Carbapenem resistance is on the rise among these gram negative bacterial isolates.

KEYWORDS: BAL, Bacteria, Antibiotic resistance.

INTRODUCTION: Pneumonia is an inflammatory condition of the lung caused by bacteria, viruses and less commonly by fungi and parasites. ${ }^{1}$

Bacteria are the most common cause of pneumonia, the common bacterial pathogens being Pseudomonas aeruginosa, Klebsiella pneumoniae, Staphylococcus aureus, Acinetobacter spp, Streptococcus pneumoniae, Escherichia coli, Enterobacter spp., Haemophilus influenzae, Moraxella spp. ${ }^{1}$ Antibiotic resistance is common among the bacterial isolates. ${ }^{2}$

Several risk factors have been identified for development of pneumonia which include age $>65$ years, smoking, alcoholism, immunosuppressive conditions and conditions such as COPD, cardiovascular disease, cerebrovascular disease, chronic liver or renal disease, diabetes mellitus and dementia. ${ }^{3,4}$

Early diagnosis and proper choice of antimicrobials are crucial for successful management of pneumonia ${ }^{5}$. The useful method of diagnosis of pneumonia is quantitative culture of bronchoalveolar lavage (BAL) samples. ${ }^{5}$ 
The spectrum of bacterial pathogens and their antibiogram varies in each setting. This study was taken up to study the spectrum of bacteria isolated from BAL with their antibiogram, in our setup.

MATERIALS AND METHODS: This retrospective study was carried out in a tertiary care hospital at Mangalore, South India for a period 1 year (March 2013-February 2014).

Sample size was 307with 95\% confidence level and 85\% power. The study included patients over 18 years of age, with clinical suspicion of pneumonia. BAL was collected through flexible bronchoscopy in all cases. All samples were cultured on Mac Conkey's agar, sheep blood agar and chocolate agar. Plates were incubated at $37^{\circ} \mathrm{C}$ overnight and a positive quantitative culture was defined when bacteria were cultured from BAL samples at a concentration of $1 \times 10^{4} \mathrm{CFU} / \mathrm{mL}$ or more. ${ }^{4}$ The organism isolated was identified and sensitivity to various antibiotics was assessed using the Modified Kirby - Bauer disk diffusion method.

RESULTS: Of the 307 BAL samples studies, 110(35.8\%) of the samples had growth of bacteria ( $\geq 10^{4}$ $\mathrm{CFU} / \mathrm{ml}$ ), 105 samples (34.2\%) yielded no growth and 95 (29.9\%) of samples had no significant growth. The spectrum of bacterial isolates is shown in Table 1. The antibiotic sensitivity pattern of Gram positive cocci and Gram negative bacilli are shown in Tables 2 and 3 respectively.

DISCUSSION: Pneumonia is inflammation of the lung, most commonly caused by bacteria. To arrive at a diagnosis, quantitative culture of BAL plays an important role. The knowledge of the bacterial pathogens with their antibiogram in the setup helps in better management of cases of pneumonia. In quantitative cultures of BAL in our study, positive culture yield was $35.8 \%$, which is comparable with results of other studies. ${ }^{4}$

In our study, Pseudomonas spp. was the most common bacterial isolate followed by Acinetobacter spp. A study performed in the medical wards of tertiary care teaching hospital in South India had the most common isolate as Pseudomonas aeruginosa $35.7 \%$ followed by Klebsiellaspp. ${ }^{6}$ In a study performed at Medical college in Korea involving 340 patients, the common bacterial isolates in 18 positive cultures included MRSA, Acinetobacter baumannii and Pseudomonas aeruginosa. ${ }^{4}$ We have not distinguished between cases of community acquired and nosocomial pneumonia.

Antibiotic resistance is emerging among Gram negative bacterial isolates especially among the nosocomial pathogens. ${ }^{7,8}$

Carbapenem resistance was seen in $22 \%$ of the isolates of Klebsiella spp. and 5 of 16 Klebsiella spp. were ESBL producers.

Acinetobacter spp. showed highest sensitivity to Cefaperazone sulbactam (84.6\%).Carbapenem resistance was seen in 31.6\% of the isolates and this high carbapenem resistance could be because of the hospital origin of the isolates. ${ }^{9,10}$

Pseudomonas spp. showed good sensitivity to cephalosporins $84 \%$, ciprofloxacin 78\%, carbapenems 85\%, and Piperacillin-Tazobactam 95\%.This is in contrast to the other studies where levels of resistance to cephalosporins and carbapenems was high(38\%).11

In our study, all strains of S. aureus were sensitive to vancomycin and teicoplanin and 5 of 14 isolates were MRSA. Enterococci showed 100\% sensitivity to vancomycin, teicoplanin and high level aminoglycosides, which is similar to the previous studies. 
IMPLICATIONS OF THE STUDY: The study provides data regarding the incidence rate of various bacterial pathogens isolated from BAL in our setup along with their antibiogram. The majority of significant bacterial isolates from BAL included Pseudomonas spp. and Acinetobacter spp. Carbapenem resistance is on the rise among the Gram negative bacilli.

\section{REFERENCES:}

1. Rahul M, Bharti C, Shobitha R, Kiran C. Bacterial isolates from the bronchoalveolar lavage fluid of patients with pneumonia not responding to initial antimicrobial therapy. Sahel Med J 2013; 16: 102-6.

2. Baik I, Curhan GC, Rimm EB, et al. A prospective study of age and lifestyle factors in relation to community-acquired pneumonia in US men and women. Arch Intern Med 2000; 160: 3082-8.

3. Koivalu I, Sten M, Makela PH. Risk factors for pneumonia in the elderly. Am J Med 1994; 96: 313-20.

4. Eun Sun, Kim, Eui-Chong Kim, Sang-Min Lee et al. Bacterial Yield from Quantitative Cultures of Bronchoalveolar Lavage Fluid in Patients with Pneumonia on Antimicrobial Therapy. Korean J Intern Med. Jun 2012; 27(2): 156-162.

5. Hummel M, Rudert S, Hof H, Hehlmann R, Buchheidt D. Diagnosticyield of bronchoscopy with bronchoalveolar lavage in febrile patients with hematologic malignancies and pulmonary infiltrates. Ann Hematol 2008; 87: 291-297.

6. Peripi SB, Thadepalli VG, Khagga M, Tripuraribhatla PK, Bharadwaj DK. Profile of antibiotic consumption, sensitivity and resistance in an urban area of Andhra Pradesh, India. Singapore Med J 2012; 53: 268-72.

7. Cantral DE, Tape TG, Reed EC, Spurzem JR, Rennard SI, Thompson AB. Quantitative culture of bronchoalveolar lavage fluid for the diagnosis of bacterial pneumonia. Am J Med. 1993; 95: 601-607.

8. Kottmann RM, Kelly J, Lyda E, et al. Bronchoscopy with bronchoalveolar lavage: determinants of yield and impact on management in immunosuppressed patients. Thorax. 2011; 66: 823.

9. Mizgerd JP. Acute lower respiratory tract infection. N Engl J Med 2008; 358: 716-727.

10. Gladstone $\mathrm{P}$, Rajendran $\mathrm{P}$, Brahmadathan $\mathrm{KN}$. Incidence of carbapenem resistant non fermenting gram negative bacilli from patients with respiratory infections in the intensive care units. Indian J Med Microbiol 2005; 23: 189-91.

11. Sisto A, D’Ancona F, Meledandri M, Pantosti A, Rossolini GM, Raglio A, et al. Carbapenem nonsusceptible Klebsiella pneumonia from Micronetwork hospitals, Italy, 2009 to 2012. Euro Surveill 2012; 17: pi: 20247. 


\begin{tabular}{|c|c|}
\hline Bacterial isolates & Number (\%) \\
\hline Pseudomonas spp. & $24(21.80)$ \\
\hline Acinetobacter spp. & $17(15.45)$ \\
\hline Klebsiella spp. & $16(14.45)$ \\
\hline Staphylococcus aureus & $14(12.72)$ \\
\hline Enterococcus spp. & $12(10.9)$ \\
\hline Streptococcus pneumoniae & $9(8.18)$ \\
\hline Others (Moraxella, Haemophilus spp.) & $18(16.36)$ \\
\hline Total & 110 \\
\hline
\end{tabular}

\begin{tabular}{|l|c|c|}
\hline \multicolumn{1}{|c|}{ Antibiotics } & Enterococcus spp. & S. aureus \\
\hline Ampicillin & 100 & Not done \\
\hline Erythromycin & Not done & 63.3 \\
\hline Gentamicin & Not done & 78.57 \\
\hline HLG andHLS & 100 & Not done \\
\hline Penicillin & 23.3 & Not done \\
\hline Vancomycin & 100 & 100 \\
\hline
\end{tabular}

Table 2: Antibiotic sensitivity pattern of Gram positive cocci from BAL in \%.*

*Sensitivity is expressed as percentage

\begin{tabular}{|l|c|c|c|}
\hline \multicolumn{1}{|c|}{ Antibiotic } & Klebsiella spp. & Acinetobacter spp. & Pseudomonasspp. \\
\hline Ampicillin & 14.2 & Not done & 16 \\
\hline Ceftazidime & 41.2 & 33.3 & 84.2 \\
\hline Cefotaxime & 46.6 & 21 & 71.4 \\
\hline Ciprofloxacin & 66.6 & 50 & 78.9 \\
\hline Cefaperazone + sulbactum & 85.7 & 84.61 & 85.7 \\
\hline Gentamicin & 100 & 66.6 & 57.89 \\
\hline Imipenem & 100 & 62.5 & 100 \\
\hline Meropenem & 92.85 & 46.6 & 86.36 \\
\hline \multicolumn{2}{|c|}{ Table 3: Antibiotic sensitivity pattern of Gram negative bacilli from BAL in \%* } \\
\hline
\end{tabular}

*Sensitivity is expressed as percentage 


\section{ORIGINAL ARTICLE}

\section{AUTHORS:}

1. Sowmya K. N.

2. Sevitha Bhat

3. K. Vishwas Saralaya

\section{PARTICULARS OF CONTRIBUTORS:}

1. PG Student, Department of Microbiology, Kasturba Medical College, Mangalore.

2. Associate Professor, Department of Microbiology, Kasturba Medical College, Mangalore.

3. Associate Professor, Department of Microbiology, Kasturba Medical College, Mangalore.

\section{NAME ADDRESS EMAIL ID OF THE} CORRESPONDING AUTHOR:

Dr. Sevitha Bhat,

Flat 102, Meadows,

Mannagudda Road, Ballalbagh,

Mangalore, Karnataka.

Email: sevitha@rediffmail.com

Date of Submission: 30/06/2014.

Date of Peer Review: 01/07/2014.

Date of Acceptance: 08/07/2014.

Date of Publishing: 14/07/2014. 